\title{
Secondary postpartum haemorrhage in a tertiary care hospital of North India: a retrospective analysis
}

\author{
Waseeqa Nigeen $^{1 *}$, Mariya Farooq ${ }^{1}$, Asima Afzal ${ }^{1}$, Sameena Ashraf $^{1}$, Abdus Sami Bhat ${ }^{2}$
}

\begin{abstract}
${ }^{1}$ Department of Obstetrics and Gynecology, Lalla Ded Maternity Hospital, An Associated Hospital of Government Medical College Srinagar, Jammu Kashmir, India

${ }^{2}$ Department of Paediatrics, G B Pant Children Hospital Srinagar, An Associated Hospital of Government Medical College Srinagar, Jammu Kashmir, India
\end{abstract}

Received: 16 November 2016

Accepted: 13 December 2016

\section{*Correspondence:}

Dr. Waseeqa Nigeen,

E-mail: samiaiims@gmail.com

Copyright: ( ) the author(s), publisher and licensee Medip Academy. This is an open-access article distributed under the terms of the Creative Commons Attribution Non-Commercial License, which permits unrestricted non-commercial use, distribution, and reproduction in any medium, provided the original work is properly cited.

\begin{abstract}
Background: Postpartum haemorrhage (PPH) is a very common complication that follows delivery. It is one of the leading causes of maternal mortality both in developing and developed countries. Primary PPH has been studied a lot, but data regarding secondary PPH is sparse. Our objective was to study the clinical characteristics and outcome of patients presenting with secondary PPH

Methods: A retrospective descriptive study done at Lalla Ded hospital Srinagar, a tertiary care hospital of North India, between June 2015 and December 2015.

Results: Fifty patients with secondary PPH were studied out of whom 36 were delivered outside this hospital and referred. Fourteen patients who delivered in this hospital developed secondary PPH. Mean age of patients was 35 \pm 3 years. Retained products of contraception (RPOCs) was the leading cause in $36(72 \%)$ of patients followed by endometritis in ten (20\%). Mean hemoglobin concentration was $8.7 \pm 1.9$ grams ranging from 4.4 grams to 12.9 grams. Mean hospital stay was $6.3 \pm 1.5$ days ranging from 1 day to 20 days. Curettage was done in $40(80 \%)$ of patients including 36 having RPOC $s$ and check curettage in four patients. Fourteen (28\%) patients required blood transfusion. One patient required hysterectomy. None of the patients died.

Conclusions: Secondary PPH has been studied very little. Our results show retained products of contraception as a leading cause of secondary PPH which is probably related to poor management of third stage of labour. There is crucial role of active management of third stage of labour in preventing secondary PPH. Majority of secondary PPH patients require dilatation and curettage with other supportive measures only. Surgical intervention is rarely required. Blood loss is usually mild to moderate. Prognosis is good if medical intervention is sought early.
\end{abstract}

Keywords: Outcome, Risk factors, Secondary post partum haemorrhage

\section{INTRODUCTION}

Post partum haemorrahge (PPH) occurs quite frequently after delivery and its incidence has been reported as $2 \%$ $4 \%$ after vaginal delivery and $6 \%$ after caesarean section. ${ }^{1}$ PPH is the most common cause of maternal mortality and accounts for $28 \%$ of all maternal deaths in developing countries and 13\% maternal deaths in high income countries. ${ }^{2}$ Primary PPH occurs within 24 hours of delivery and is not the subject of our study. Secondary postpartum hemorrhage is classically defined as haemorrhage in excess of lochia occurring between 24hours after delivery up to six weeks post partum. The rationale behind differentiating these two types of PPH lies in the fact that the predominant causes leading to these are different. While uterine atony is the leading cause of primary PPH, retained products of conception cause secondary PPH most of the time. ${ }^{1,3-6}$ Secondary 
PPH can be caused by numerous other etiologies the significant among which are, primary subinvolution of placental bed, endometritis, pseudoanuerysm of the uterine artery, non union of uterine incision etc. ${ }^{6-9}$ Other rare causes of $\mathrm{PPH}$ have also been reported. ${ }^{10,11}$ While there is plenty of data available in world literature regarding primary $\mathrm{PPH}$, secondary $\mathrm{PPH}$ has not been studied with similar zeal. The reason is simply because secondary PPH is not perceived to contribute much to the maternal mortality and morbidity. Data from Indian subcontinent is sparse. We aimed to find out the incidence, causes and outcome of patients who presented to our hospital with secondary PPH.

\section{METHODS}

It was a retrospective type of study in which case records of all patients admitted to a tertiary care hospital of north Indian state of Jammu and Kashmir with a diagnosis of secondary PPH over a period of six months between June 2015 and December 2015 were reviewed for relevant information. The hospital caters to almost all tertiary care referrals from Kashmir division and some areas of adjoining Jammu and Ladakh division. Information regarding previous obstetric history, antenatal course, intranatal course, mode of delivery, place of delivery, immediate postpartum period, day of presentation after delivery, total hospital stay, treatment given and final outcome vis a vis discharge or death was recorded. We also looked for the history of manual removal of placenta and primary $\mathrm{PPH}$ as two of the important risk factors for secondary PPH. Patients in whom case records were incomplete and lacked any of the information we required were excluded. Etiology related to cause of secondary $\mathrm{PPH}$ as recorded in case sheets was taken as final as the hospital follows strict protocols for diagnosis and management of these patients. Results are presented in numbers and proportions. Ethical approval was taken from the Institutional ethics committee.

\section{RESULTS}

Out of total 11560 admissions in the hospital (including booked and referrals) in the same time period for various obstetric complications, 553 patients were admitted because of postpartum complications. Fifty four $(0.5 \%$ of total and $11 \%$ of postpartum) admissions were because of secondary PPH. Four patients were excluded from the final analysis because of incomplete details mentioned in case sheets. During the study period there were total 7912 live births in the hospital, out of which 5562 were caesarean deliveries and 2350 were vaginal deliveries. Eight patients $(0.15 \%)$ who had delivered by caesarean section in our hospital developed secondary PPH, while six $(0.26 \%)$ of patients who delivered vaginally developed secondary PPH (Table 1).

Table 1: Hospital based incidence of secondary post partum haemorrhage.

\begin{tabular}{|lll|}
\hline & Number & $\begin{array}{l}\text { Number with secondary } \\
\text { PPH (percentage) }\end{array}$ \\
\hline Total hospital admissions for obstetric complications & 11560 & $54(0.5 \%)$ \\
\hline $\begin{array}{l}\text { Total admissions for postpartum complications including } \\
\text { referrals }\end{array}$ & 553 & $54(11 \%)$ \\
\hline Total live births in our hospital & 7912 & $14(0.18 \%)$ \\
\hline Total caesarean deliveries in our hospital & 5562 & $8(0.14 \%)$ \\
\hline Total vaginal deliveries in our hospital & 2350 & $6(0.26 \%)$ \\
\hline Admissions for other obstetric reasons & 3095 & \\
\hline
\end{tabular}

The mean age of the patients were $35 \pm 3$ years ranging from 28 to 40 years. Mean time to presentation after delivery was $11.12 \pm 4.7$ days with a range of 3 days to 24 days. Baseline characteristics of the patients are given in Table 2 . Thirty four $(68 \%)$ were vaginal deliveries and rest were caesarean. $36(72 \%)$ were referred cases and were handled outside our hospital before presentation.

History of manual removal of placenta was found in 4 (8\%) cases while $2(4 \%)$ patients had history of primary PPH. Fourteen $(28 \%)$ patients had fever on presentation. Four $(8 \%)$ patients were in shock. Mean hemoglobin concentration was $8.7 \pm 1.9$ grams ranging from 4.4 grams to 12.9 grams (Table 2). Retained products of contraception (RPOCs) was the leading cause in 36
(72\%) of patients followed by endometritis in ten (20\%). In four patients cause could not be ascertained beyond doubt. Causes of secondary PPH in present patients are given in Table 3.

Antibiotics were given in all patients as a policy of the hospital. Curettage was done in $40(80 \%)$ of patients including 36 having RPOCs and check curettage in four patients. Fourteen (28\%) patients required blood transfusion. Overall twenty two units of blood were transfused in these patients ranging from one unit to three units per patient as per requirement. Three patients $(6 \%)$ required inotropic support (two dopamine alone, one dopamine and adrenaline). 
One patient had to undergo emergency transabdominal hysterectomy because her bleeding continued even after curettage and other supportive management and patient landed into haemorrhagic shock (Table 4).

Table 2: Baseline variables of patients with secondary post partum haemorrhage.

\begin{tabular}{|ll|}
\hline Baseline variables & Number $(\mathbf{5 0})$ \\
\hline Age (mean \pm SD) years & $35 \pm 3$ \\
\hline Parity (Primi) $(\%)$ & $12(24 \%)$ \\
\hline Mode of delivery (NVD) $(\%)$ & $34(68 \%)$ \\
\hline Place of delivery (referred) $(\%)$ & $36(72 \%)$ \\
\hline Time to presentation after delivery (Mean \pm SD) days & $11.12 \pm 4.7$ \\
\hline Fever $(\%)$ & $14(28 \%)$ \\
\hline Shock $(\%)$ & $4(8 \%)$ \\
\hline Manual removal of placenta $(\%)$ & $4(8 \%)$ \\
\hline Primary PPH history $(\%)$ & $6(12 \%)$ \\
\hline Hemoglobin (Mean \pm SD) grams/dl & $8.7 \pm 1.9$ \\
\hline
\end{tabular}

Table 3: Causes of secondary postpartum haemorrhage.

\begin{tabular}{|ll|}
\hline Cause & Number (\%) \\
\hline Retained products of contraception & $36(72 \%)$ \\
\hline Endometritis & $10(20 \%)$ \\
\hline Cause not found & $4(8 \%)$ \\
\hline
\end{tabular}

Table 4: Intervention required.

\begin{tabular}{|ll|}
\hline Intervention & Number (\%) \\
\hline $\begin{array}{l}\text { Dilatation and curettage/Suction } \\
\text { evacuation }\end{array}$ & $40(80 \%)$ \\
\hline Antibiotics & $50(100 \%)$ \\
\hline Blood transfusion & $14(28 \%)$ \\
\hline Inotropic support & $3(6 \%)$ \\
\hline Hysterectomy & $1(2 \%)$ \\
\hline
\end{tabular}

Mean hospital stay was $6.3 \pm 1.5$ days ranging from 1 day to 20 days. There was no death and hence contribution to overall mortality could not be ascertained.

\section{DISCUSSION}

Fifty four patients were admitted to our hospital in one year which is $0.5 \%$ of total admissions due to obstetric complications and $11 \%$ of admissions due to postpartum complications. The percentage is significant and implies that it contributes significantly to the morbidity of post partum patients. The numbers defy the lack of reliable literature regarding characterization of secondary PPH. Although less in number there have been some studies that have made similar observations. A study done in Africa revealed that about one third of the total PPH cases had secondary PPH. Similar study done in Nepal revealed secondary PPH as the cause of about $32 \%$ cases of PPH. ${ }^{5,12}$ Sixty eight percent of our patients had vaginal delivery, however it cannot be said that vaginal delivery predisposes to secondary PPH as the overall vaginal deliveries are more as compared to caesarean deliveries. Thirty six (72\%) cases were referred from outside. Since we had a large number of referred patients who had come from outside, incidence following vaginal delivery vis a vis caesarean delivery could not be ascertained because we did not know the actual number of vaginal or caesarean deliveries from among whom these patients had developed PPH and also we did not know how many of secondary PPH patients were managed in peripheral hospitals and not referred.

However among patients delivered in our hospital overall incidence was very low probably because of active management of third stage of labour. The incidence following vaginal delivery in our hospital was $0.26 \%$ and incidence following caesarean delivery in our hospital was $0.15 \%$. The number is expected to be higher in patients delivered at home or handled by unskilled midwives. Indirectly we might conclude that skilled supervision of delivery and labour including active management of third stage of labour decreases the risk of secondary PPH. Active management of third stage of labour has been followed as a strategy to prevent PPH including secondary PPH. ${ }^{12}$

Prolonged third stage of labour has been shown to increase the risk of secondary PPH. ${ }^{13}$ The observation that unbooked and unsupervised pregnancies coupled with unskilled deliveries or home deliveries lead to increased risk of both primary and secondary PPH has been well established. ${ }^{4,5}$ This also explains the fact that most of our secondary PPH patients were either unbooked or referred. Twenty four percent of cases were primiparous. However no conclusion regarding multiparity being a risk factor for secondary PPH can be drawn. 
Multiparity has been found as risk factor for secondary PPH in other studies. ${ }^{4}$ Manual removal of placenta and history of primary PPH was found in $8 \%$ and $12 \%$ of our patients. These two risk factors have been associated with secondary PPH and all steps should be taken to prevent these. ${ }^{14,15}$ Mean age of our patients was $35 \pm 3$ years. This corroborates with previous studies where age more than 35 years was found to be associated with increased risk of secondary PPH. ${ }^{4,15}$

Retained products of contraception was documented as a possible cause in maximum number of patients $(72 \%)$ which is consistent with previous studies. ${ }^{5,6}$ It signifies the role of unskilled and unhealthy delivery practices as a leading risk factor for secondary $\mathrm{PPH}$.

Fourteen (28\%) patients had fever but endometritis or infection was documented in only 10 patients $(20 \%)$ on the basis of recorded clinically foul smelling lochia and positive culture. Cause could not be ascertained in 8 patients (10\%) partly because of limited high end diagnostic facilities. Similar pattern of etiology has been reported in previous studies. 5,6

All of the patients were given antibiotics (100\%) as policy of the hospital and dilatation curettage/suction evacuation was done in $(80 \%)$ as most of our patients had RPOCs. Hysterectomy was done in one patient in whom bleeding did not stop even after curettage. This pattern of treatment options and interventions reflects the kind of protocols that are being followed in our hospital and need not be totally evidence based. Today thrust is being placed on evidence based management of secondary PPH and studies need to be done on traditional management approach of secondary PPH as has been highlighted by many studies. ${ }^{16}$

Amount of bleeding varied with each patient. Mean hemoglobin level was $8.7 \pm 1.9 \mathrm{~g}$.Blood transfusion was given in about one third of our patients. Four patients were in haemorrhagic shock at presentation and required fluid resuscitation. Three of these patients required inotropic support also. This signifies that the amount of bleeding varies greatly. While some patients might develop haemorrhagic shock, most of them do not require transfusions.

None of our patients died. Predominant maternal mortality is caused by primary $\mathrm{PPH}$, while as shown by our study also, although morbidity in secondary PPH is significant, it usually does not lead to death if such patients are properly managed.

\section{CONCLUSION}

Secondary PPH has been studied very little. Our results show retained products of contraception as a leading cause of secondary $\mathrm{PPH}$ which is probably related to poor management of third stage of labour. There is crucial role of active management of third stage of labour in preventing secondary PPH. Majority of secondary PPH patients require dilation and curettage with other supportive measures only. Surgical intervention is rarely required. Blood loss is usually mild to moderate. Prognosis is good if medical intervention is sought early.

Funding: No funding sources

Conflict of interest: None declared

Ethical approval: The study was approved by the Institutional Ethics Committee

\section{REFERENCES}

1. Amy JJ. Severe Postpartum Hemorrhage: A Rational Approach. Nat Med Journ Ind. 1998;11:86-8.

2. Khan KS. WHO Analysis of Causes of Maternal Death: A Systematic Review. The Lancet. 2006;367:1066-74.

3. Klufio CA, Amoa AB, Kariwiga G. Primary postpartum haemorrhage: causes, aetiological risk factors, prevention and management. P N G Med J. 1995;38(2):133-49.

4. Jaleel R, Khan A Post-partum haemorrhage--a risk factor analysis. Mymensingh Med J. 2010;19(2):2829.

5. Ajenifuja KO, Adepiti CA, Ogunniyi SO. Post partum haemorrhage in a teaching hospital in Nigeria: a 5-year experience. African Health Sciences. 2010;10(1):71-4.

6. Dossou M, Debost-Legrand A, Déchelotte P Lémery D,Vendittelli F. Severe secondary postpartum hemorrhage: a historical cohort. Birth. 2015;42(2):149-55.

7. Mammen T, Shanthakumari H, Gopi K, Lionel J, Ayyappan AP, Kekre A. Iatrogenic secondary postpartum haemorrhage: apropos of two uncommon cases. Australas Radiol. 2006;50(4):392-4.

8. Nanda S, Singhal S, Sharma D, Sood M, Singhal SK. Nonunion of uterine incision: a rare cause of secondary postpartum haemorrhage: a report of 2 cases. Aust N Z J Obstet Gynaecol. 1997;37(4):4756.

9. Larsen JV , Janowski K, Krolilowski A Secondary post partum haemorrhage due to uterine wound dehiscence. Cent Afr J Med. 1995;41(9):294-6.

10. Sharma JB, Gupta N, Vimala N, Anand M, Deka D, Mittal SArch Gynecol Obstet. Acute promyelocytic leukemia: an unusual cause of fatal secondary postpartum hemorrhage. 2006;273(5):310-1.

11. Kelly SM, Belli AM, Campbell S. Hoveyda F. Arteriovenous malformation of the uterus associated with secondary postpartum hemorrhage. Ultrasound Obstet Gynecol. 2003;21(6):602-5

12. Dongol AS, Shrestha A, Chawla CD Post partum haemorrhage: prevalence, morbidity and management pattern in Dhulikhel Hospital. Kathmandu Univ Med J (KUMJ). 2010;8(30):212-5.

13. Magann EF, Doherty DA, Briery CM, Niederhauser A, Chauhan SP, Morrison JC. Obstetric characteristics for a prolonged third stage of labor 
and risk for postpartum hemorrhage. Gynecol Obstet Invest. 2008;65(3):201-5.

14. MacKenzie I. Secondary PPH: Incidence, morbidity and current management. British Journal of Obstetrics and Gynaecology. 2001;108:927-30.

15. Debost-Legrand A, Rivière O, Dossou M, Vendittelli F, Risk Factors for Severe Secondary Postpartum Hemorrhages: A Historical Cohort Study. Birth. 2015;42(3):235-41.
16. Babarinsa IA, Hayman RG, Draycott TJ Secondary post-partum haemorrhage: challenges in evidencebased causes and management. Eur J Obstet Gynecol Reprod Biol. 2011;159(2):255-60.

Cite this article as: Nigeen W, Farooq M, Faroq M, Ashraf S, Bhat AS. Secondary postpartum haemorrhage in a tertiary care hospital of North India: a retrospective analysis. Int J Reprod Contracept Obstet Gynecol 2017;6:532-6. 